MLM- -3677

DE91 007664

\title{
Measurement Control Administration for Nuclear Materials Accountability
}

Clifford R. Rudy

Issued: January 31, 1991

\section{MOUND}

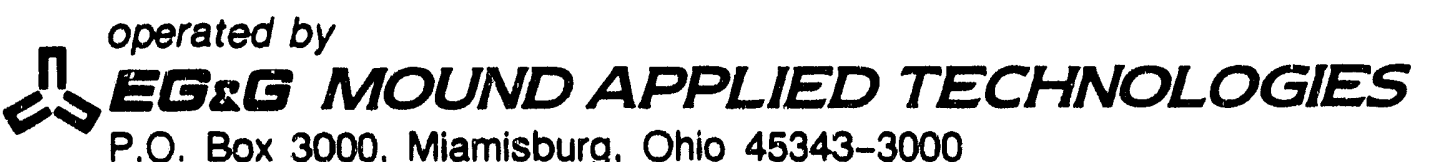

P.O. Box 3000. Miamisburg, Ohio 45343-3000

for the

U. S. DEPARTMENT OF ENERGY

MASTER

Contract No. DE-AC04-88DP43495 


\section{Contents}

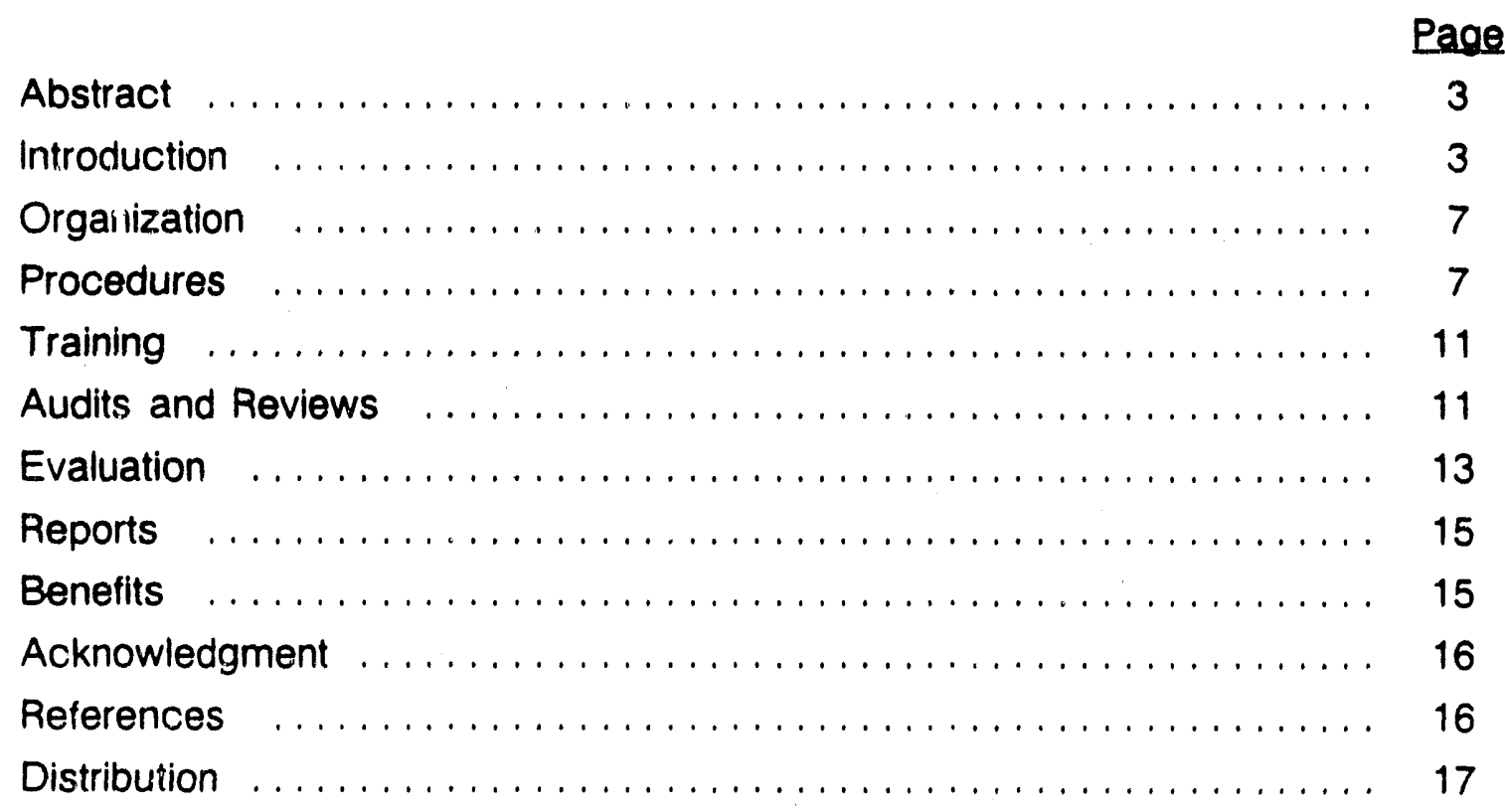




\section{Abstract}

In 1986 a measurement control program was instituted at Mound to ensure that measurement performance used for nuclear material accountability was properly monitored and documented. The organization and management of various aspects of the program are discussed.

\section{Introduction}

Accurate measurements are the basis of nuclear material accountability. The validity of the accountability values depends on the measurement results that are used to determine inventories, receipts, and shipments. With this measurement information. material balances are calculated to determine losses and gains of materials during a specific time period. Inventory Differences (ID) are calculated according to the following equation:

$$
I D=B E G I N V+\text { RECEIPTS - SHIPMENTS - END INV }
$$

Each term in this equation is based on chemical or physical measurements of many items. The validity of each term is dependent on the component measurements. Thus. in Figure 1, the measured element weight of $17 \mathrm{~g}$ is dependent on the performance of the particular measurement system that was used. In this case, the measurement is performed using a passive gamma ray method with a calibration curve determined by measuring representative standards containing a range of special nuclear materials (Figure 2). One objective of a measurement control program is to monitor and verify the validity of the calibration curve (Figure 3).

In 1986 Mound's Nuclear Materials Accountabilitv (NMA) group instituted a formal measurement control program to ensure the validity of the numbers that cornprise this equation and provide a measure of how well bulk materials can be controlled. At Mound most measurements used for accountability are production measurements with their own quality assurance programs. In many cases a measurement control system is planned and maintained by the developers and operators of the particular measurement system with oversight by the management responsible for the results. 


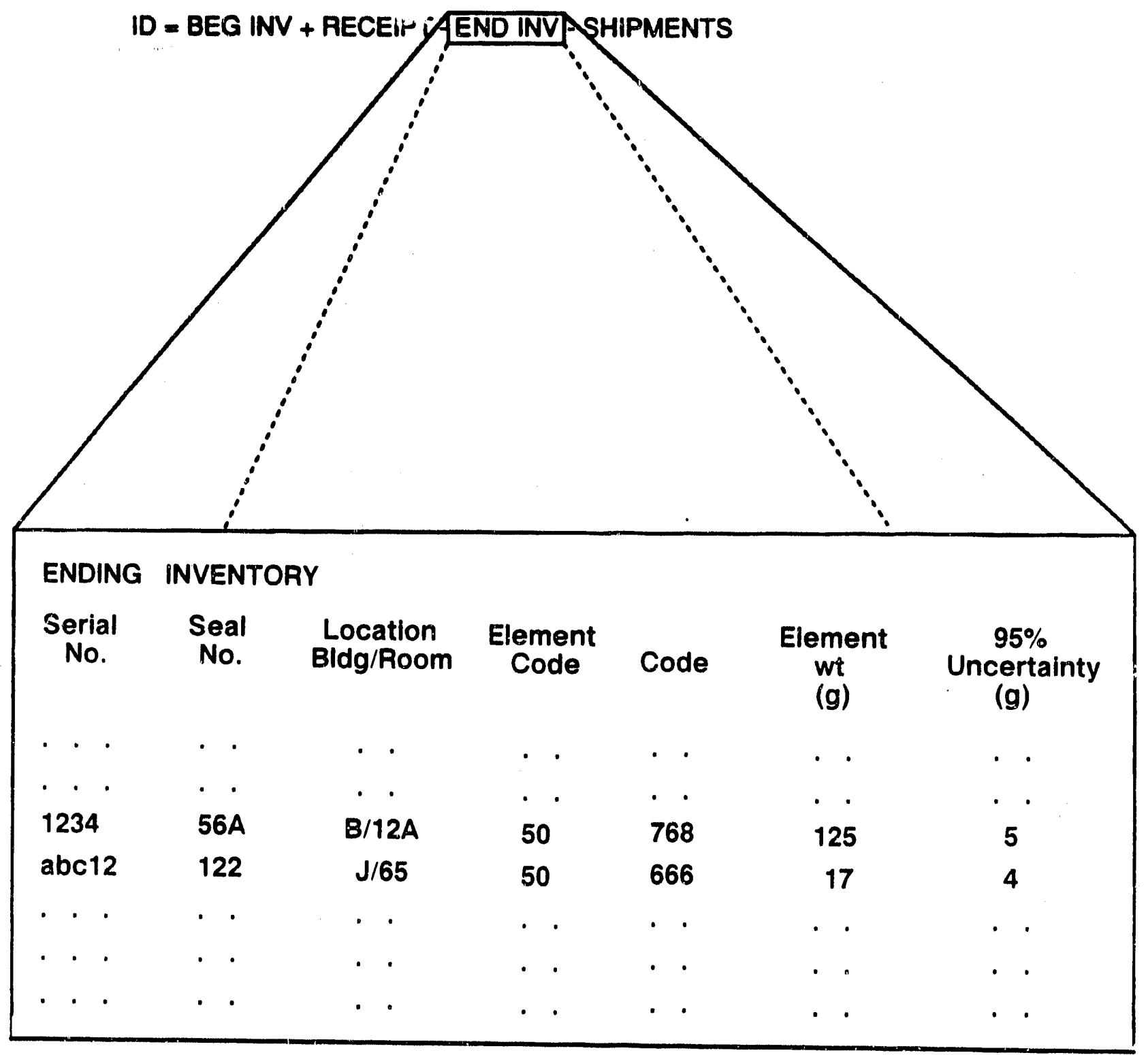

Figure 1 - Accountability quantities are based on measurements.

If production measurements are to be used for accountability purposes, then their associated material control programs should satisfy the accountability measurement control requirements specified in DOE Order 5633.3. 


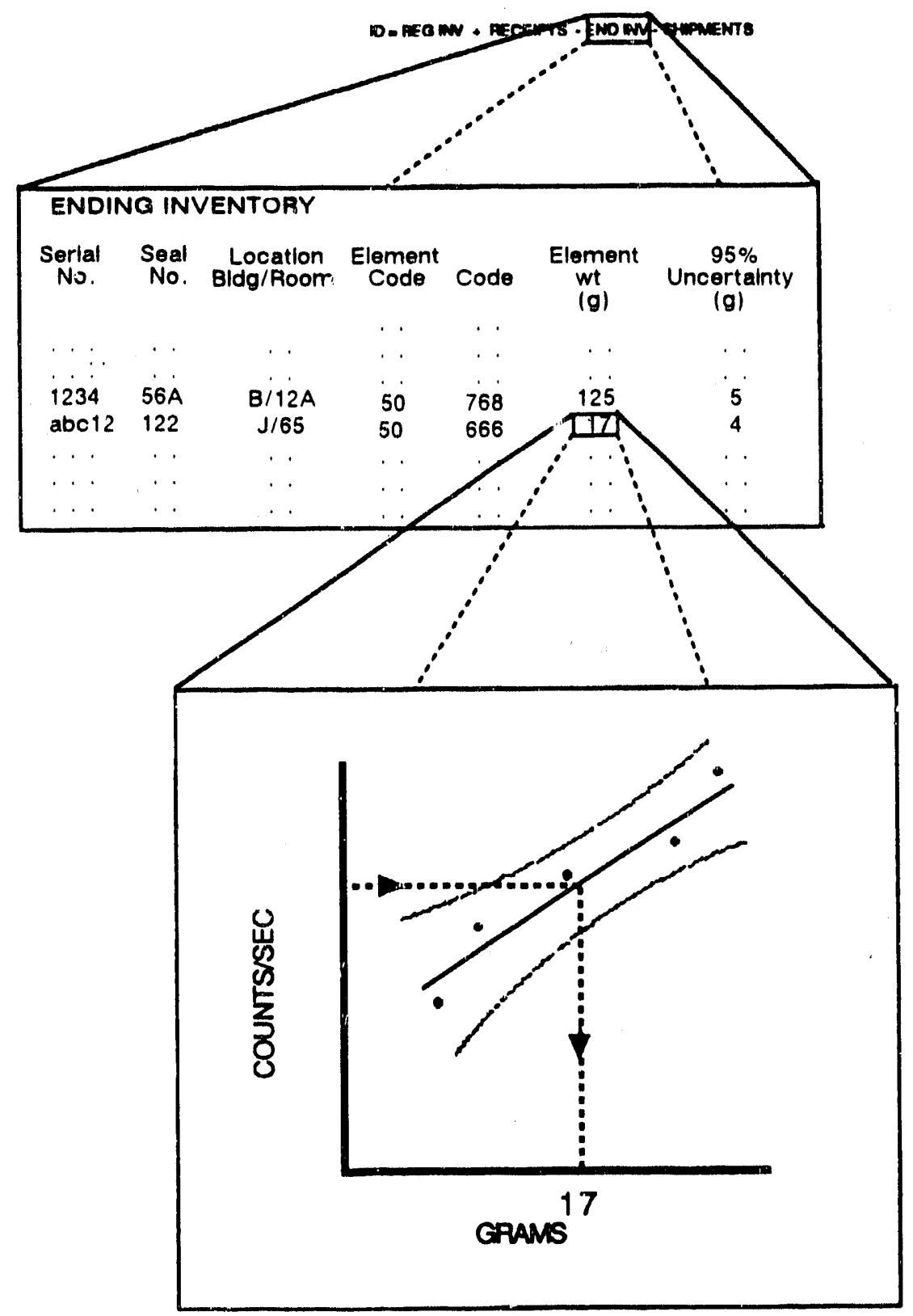

Figure 2 - Measurements are based on calibrations. 


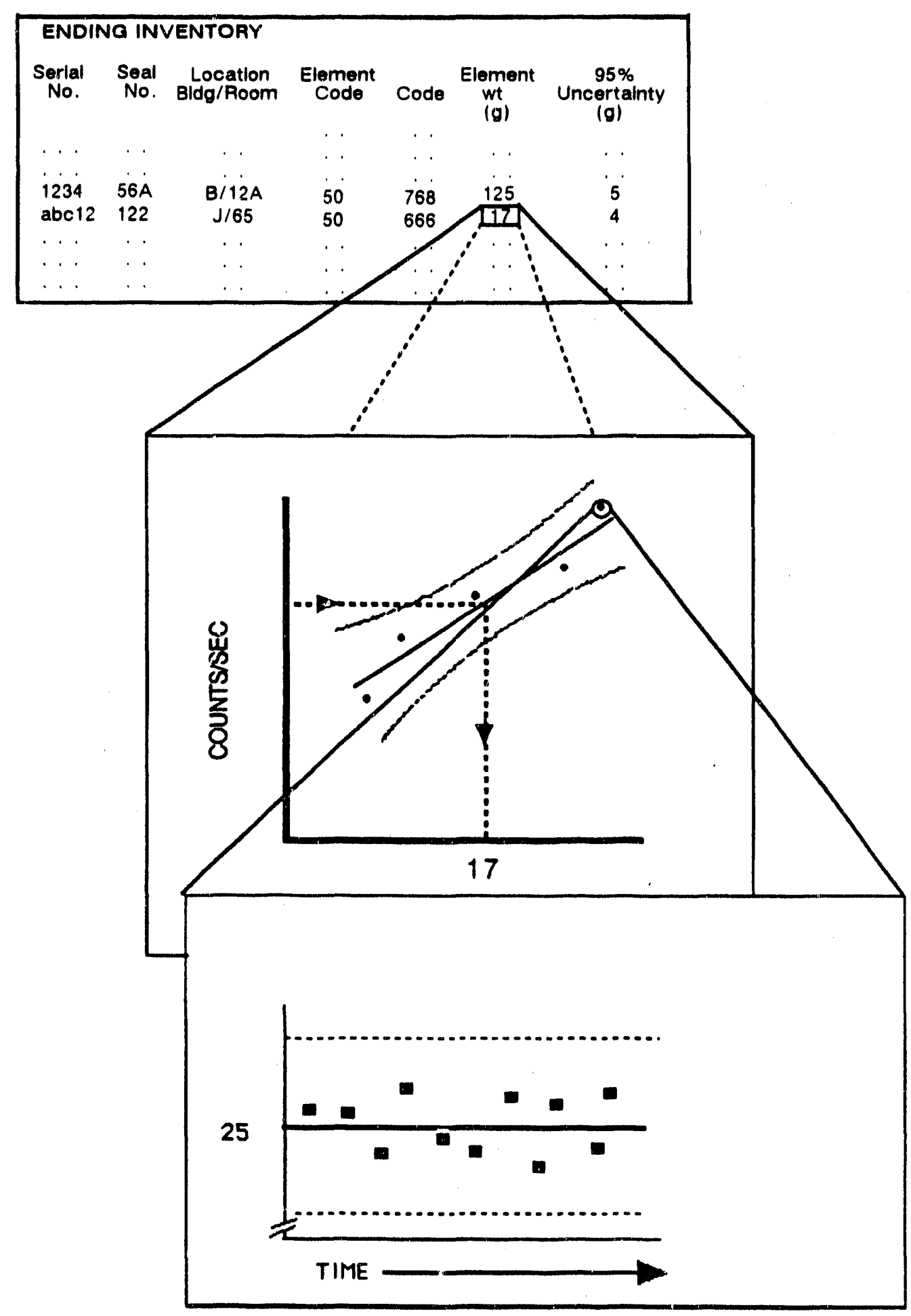

Figure 3 - Calibrations must be monitored using measurement control procedures. 


\section{Organization}

A measurement control plan was develicped that established the organizational structure required to monitor the individual measurement control procedures for each material balance area and analytical laboratory. The plan specified that one person from NMA be appointed as measurement control administrator. This administrator is responsible for managing measurement control activities supporting nuclear material accountability. In the establishment of the organizational structure it was determined that measurement control information should pass from line personnel as directly as possible to the measurement control administrator. Thus, the measurement control administrator deals directly with the line personnel performing the accountability measurements. In each material balance area or analytical system. one person is assigned responsibility for all accountability measurements.

Documentation, reporting schedule requirements, and action plans for abnormal measurement conditions were also specified in the measurement control plan. Prior to setting up the measurement control program, a series of seminars was given to familiarize line personnel with the new requirements and help them set up or modify their process measurement control plans to satisfy the new requirements. The flow of information through the organizational structure for the measurement control program is shown in Figure 4.

\section{Procedures}

As a result of the new requirements, measurement control procedures were written specifically for each material balance area at Mound in which accountability measurements are performed. In addition, existing measurement control procedures for analytical measurements performed by central laboratories were modified or written to meet the new requirements. To standardize the format and facilitate the uniform preparation of the procedures, a guideline was provided to each responsible person. The guideline specified the format and content of each section of the procedure. The suggested format was designed to deal with major aspects of measurement control. Each document contains enough detail about the process and measurements to allow 


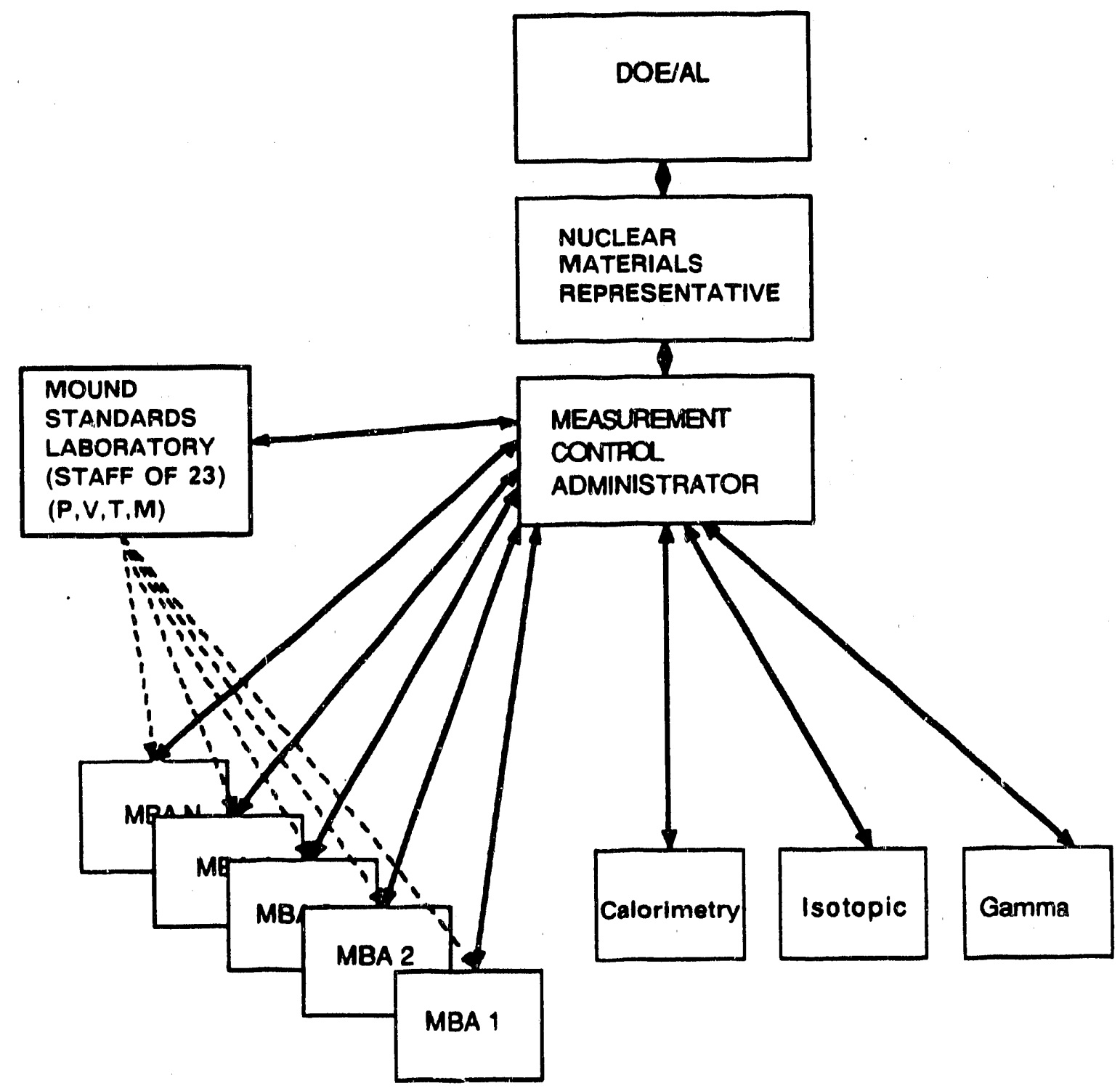

Figure 4 - Organizational relationships between Nuclear Materials Accountability and measurement control. MBAs are material balance areas.

one unfamiliar with the process to technically evaluate the measurement control system. ANSI N15-41 and USAEC guidelines proved useful in developing the format.

The major sections of the measurement control plan are structured as follows.

Section 1. Describes the process for a particular material balance area. Identifies the major process steps during normal operations and the location of 


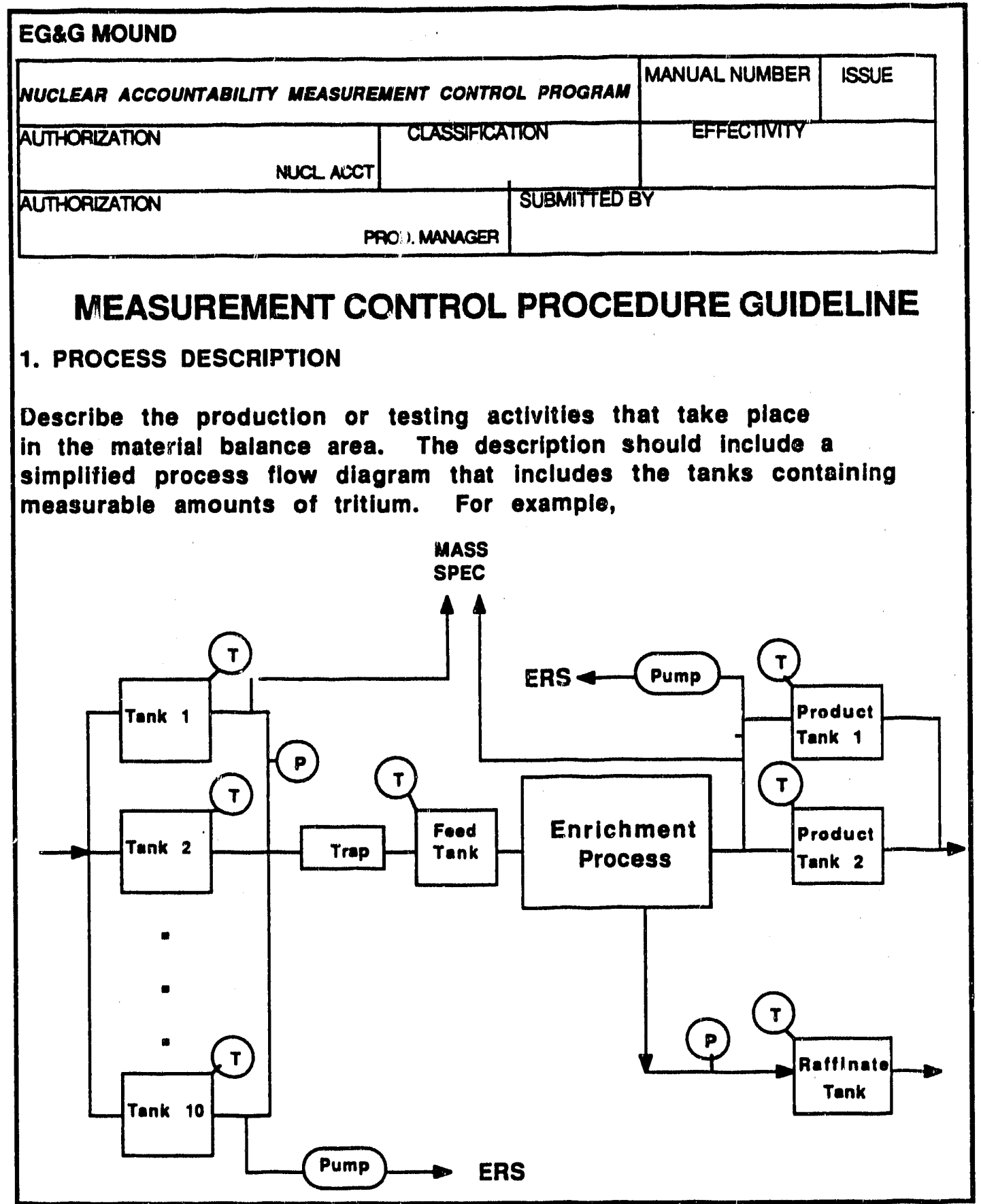

Figure 5 - Page 1 of a guideline used to prepare measurement control procedures for a process material balance area. 
accountability measurement points using simple schematics (Figure 5 shows the first page of the guideline).

Section 2. Physical Inventory. Describes the physical inventory measurements performed in the material balance area, in particular, which tanks are assayed.

Section 3. Measurement Systems. Describes the accountability measurement systems, specifying instrument identification numbers, calibration ranges, and recalibration schedule.

Section 4. Verification Procedures. Describes methods used for independently checking the veracity of the measurements and the types of control charts used to track measurement performance.

Section 5. Records and Reports. Outlines a report sent to the measurement control administrator describing measurement control activities during the previous quarter.

Section .6. Training/Qualifications. Specifies requirements for personnel performing accountability measurements.

Appendices. Descriptive appendices written by Mound Standards Laboratory personnel responsible for initial calibrations and periodic recalibrations of instruments for the measurement of pressure, volume, temperature, and mass. Includes a separate section written by the analytical staff describing gas sampling procedures to be followed by process personnel.

References. More detailed measurement procedures are referenced.

The 20 measurement control procedures that were prepared became part of the Mound Technical Manuals System. Replacement of equipment or other changes in a measurement system require changes in the appropriate measurement control procedure. The distribution of updated versions is handled through the Technical Manuals and Publications Group. Measurement control procedures are reviewed by the 
measurement control administrator and approved by the NMA representative prior to publication.

\section{Training}

Since production measurement hardware and procedures are also used for accountability measurements, most of the appropriate training for measurement control is provided while qualifying the person to perform the process operations. Every person handling tritium. for example, is required to take a one-week course on the fundamentals of tritium handling. Some parts of the process training deal specifically with tritium accountability. Practice accountability transfers of low-level bulk gas are performed between calibrated tanks under realistic conditions. A part of the training manual is shown in Figure 6. The accountability portion of the course also covers

- Mound/DOE requirements

- Measurements

- Iinventory preparation

- Gas sampling

- Computation of gram quantity

- Decay corrections

- Tritium holdup

- Potential sources of error

- Control charts, action limits

Training records are maintained by Mound's Training Section. Mound has a documented plan for the training of measurement personnel.

\section{Audits and Reviews}

The administrator verifies that the measurement control procedure accurately represents the operations taking place in the material balance area. In particular, he/she checks that the appropriate accountability instruments specified in the procedure 


\section{OPERATING NSTRUCTIONS \\ TRAINING SYSTEM HANDS-ON LAB MODULE}

General. This set of procedures is for training purposes only. It is a general set of guidelines, and serves as an example of one style of procedures writing.

The procedures are written for the transfer of low level tritium gas from tank *1 to tankt2 both in the tritium trainer station. PVTMS measurements are made pritor to the transfer and compared to those obtained afterward. NOTE: This equipment is part of an actual operating system and does have connections to other operating areas.

A process flow diagram of the trainer system is attached(Fig. 1)

Note: If at any time you do not understand the Instructlone for eny reasen, do not heaitate to ask the Instructorlil

\section{INSTRUCTIONS}

A. Obtaln PVT/MS readinge for Tunkg*1 and $\boldsymbol{* 2}$.

1. For Tank*1, close valve 16 and open valve 17. For Tank*2 close valve 12 and open valve 14.

2. The pressure readings may be taken in the control panel located on the south wall of T.61.

3. The volume for the tank and lines has been provided on the worksheets.

4. The temperature resdouts are in the control console.

5. Your instructor has provided mass spec results to be used on the worksheets.

6. Record all readings for the tank contents on the attached worksheets before proceeding.

B. Begin warming up vane pump.

1. Isolate a pumping loop to circulate gas.

a. Close valves $0,1,2$, and 11 .

b. Open values 26, 27, and 28 .

2. Tum the pump on and bugin slowly in the REVERSE direction. (Think-Why in the reverse direction?)

3. Check visual gauges on the pump to be certain there is no pressure buildup.

4. The pump should be allowed to run for about 10 minutes to warm up. (The instructor may reduce this amount of time since the pump may have been run previously.)

C. Prepare for gee transter to Tank\#2.

1. Close off lines that are unnecessary for the transfer by closing the following valves: $591,581,15,4,0,24,19,20,5,10,13,592$

(Think- Why close 581 and 15? Why close 19 and 20?)

2. Close off the tank from the pressure transducer 80 that pressure drops can be checked as the transfer line is opened by closing valve 17. 
are being used as stated. As part of production measuremerii requirements, periodic recalibrations are performed in-line on pressure transducers, thermocouples, and scales by Mound's Standards Laboratory. Calibiation tags located on or near the appropriate instruments indicate the range of operation, accuracy, and the calibration period.

The administrator chocks to make sure that accountability measurements are made with calibrated equipment and that the equipment used for the calibrations is itself certified and traceable to primary standards calibrated by the Albuquerque Primary Standards Laboratory ur by NIST (formerly NBS), thus providing a basis for accuracy claims. The same kind of checks are performed on the calibration equipment as on the accountability measurement systems. Thuis, documerits from the Mound Staridards Laboratory are audited and their traceability verified. In addition, the administrator reviews training records to verify that quaified personnel are performing the accountability measurements.

Finally. internal audits of the measurement control operations are performed by other Mound persorinel to determine the adequacy of ihe program. These auditors are not involved in routine measurement control activities.

\section{Evaluation}

Control charts are used to monitor the performance of analytical systems and material balance areas with large throughults. For measurement control, action limits are maintained for 1) , rass spestrometers on reference material with known isotopic compositions, 2) calorimeter power measurements using radioactive heat sources, 3) mass standard check weights, 4) mole balances for transfers between calibrated gas tanks. 5) cross comparisons betweer weight, calorimetry, or PVT/MS. Approximately 80 control charts are maintained at Mound. A centrol chart for tritium isotopic compositinn for one of the mass spectrometers is shown in Figure 7. Occasionally. alarm ( 3 sigma) limits are exceeded, and. if remeasuremeni indicates that the probiem is real rather than a statistical fluctuation, then the instrument is taken out of service until the problem is solved The measurement control administrator is informed of the discrepancy. 
Heat standard measurements for calorimeters are made on a weekly basis at best. since each measurement requires up to one working day. If a standard measurement exceeds the control limit, it is possible that the assays since the last in-control measurement may be biased. It is the responsibility of the measurement control

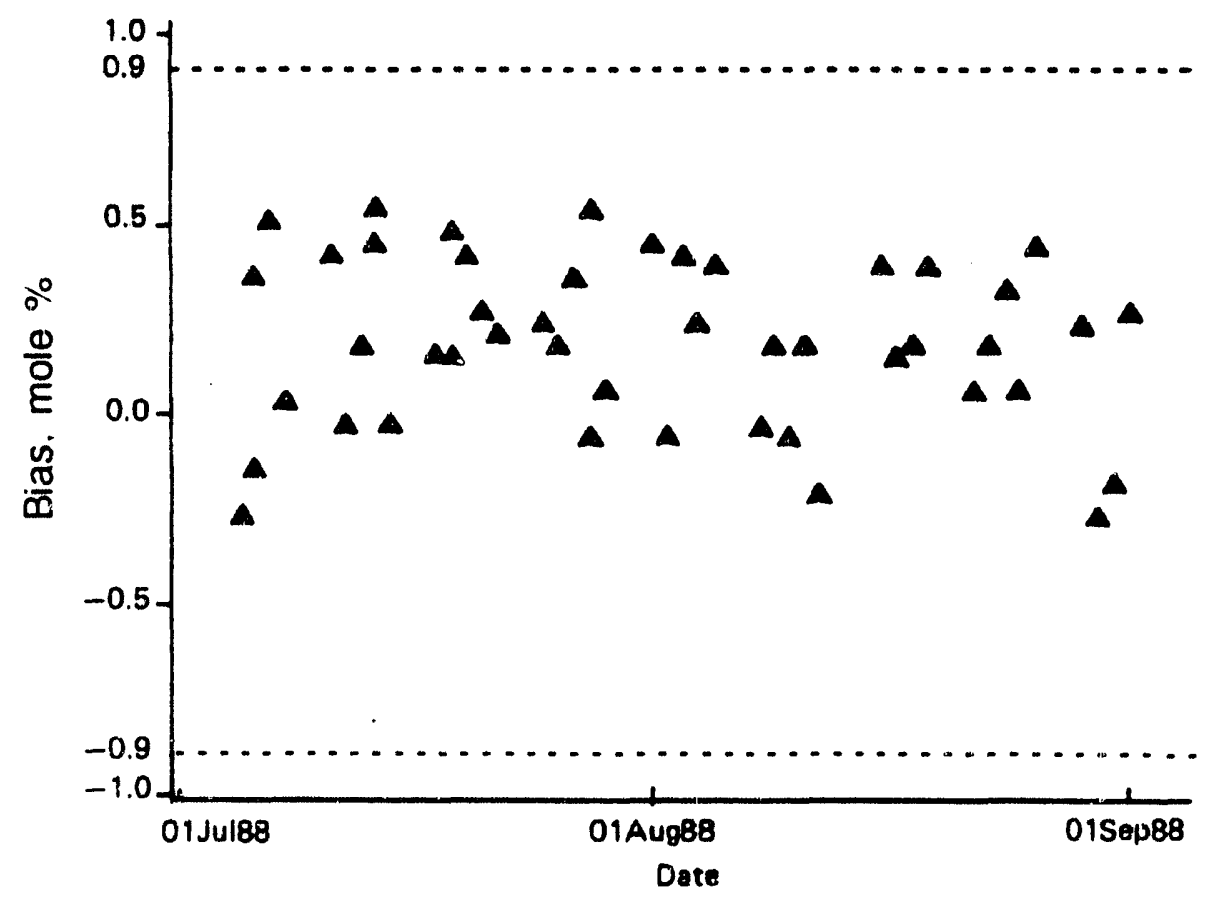

Figure 7 - Control chart of the bias (reference value - measured value) for measurement of tritium reference material. Control limits are 3 sigma.

administrator to evaluate the impact of the larger bias on the accountability records. If the power deviation leads to a mass deviation less than the smallest accountable unit, $0.01 \mathrm{~g}$ for tritium, then remeasurement is not required for that itern.

Occasionally, special studies are requested by the administrator to obtain additional supporting evidence of the accuracy of measurement results. For example. samples of waste material normally measured by calorimetry in larger 
liquid samples have been subjected to scintillation measurements to provide verification of the nondestructive assay technique.

\section{Reports}

Quarterly reports are sent from the measurement supervisor of each material balance area and analytical measurement system to the measurement control administrator. who Lises their reports to prepare a summary report for the safeguards branch of the DOE operations office. DOE/AL/NSB. The dates and, if possible, the causes of discrepant measurements exceeding control limits are reported. The actions taken as a result of these abnormalities are a part of these reports. Control charts of the most important measurements ara routinely included as part of the summary report. With hundreds of standard measurements taken each quarter, on average there should be several measurements exceeding control limits due to normal statistical fluctuations. However. although the outliers may be statistical in origin, each of the discrepant measurements exceeding the 3-sigma limits is investigated as if the bias were due to nonstatistical causes and the impact on the accountability records is evaluated by the measurement control administrator.

\section{Benefits}

A formal measurement control program provides a technical basis for demonstrating and documenting accountability measurement performance. Measurement performance information formerly scattered throughout the facility in different groups with varying measurement needs is now centralized and quickly accessible. An additional benefit is that the statistical information obtained has proven useful in evaluating the significance of the shipper-receiver differences in transfers between material balance areas at Mound and in shipments of material between Mound and other DOE facilities. This statistical information can be used for estimating the uncertainties of each accountability quantity, usually expressed as $95 \%$ confidence limits. In addition, measurement error components of the LEID (limit-of-error inventory difference) can be estimated from measurement control data. 


\section{Acknowledgment}

The author wishes to acknowledge the key role played by $\mathrm{Dr}$. $W$. Strohm in the setup of the measurement control program at Mound. Dr. Strohm prepared the first measurement control plan and organized a series of seminars in 1985 to familiarize personnel with measurement control concepts.

\section{References}

DOE Order 5633.3, Control and Accountability of Nuclear Materials (2-3-88), Chapter II. section 4e. Measurement Control. This order specifies DOE measurement control requirements for nuclear material accountability at DOE facilities.

10 CFR Part 70.57, Measurement Control Program for Special Nuclear Material Control and Accounting. This regulation specifies NRC measurement control requirements for licensee facilities possessing formula quantities of strategic special nuclear material.

ANSI N15.41-1984, Derivation of Measurement Control Programs - General Principles. This standard of the American National Standards Institute presents generic principles to be followed in the preparation of a measurement control program.

USAEC Regulatory Guide 5.45 (REG/G-5.45) Standard Format and Content for the Speciai Nuclear Material Control and Accounting Section of a Special Nuclear Material License Application (including That for a Uranium Enrichment Facility), December 1974. Sections of this Atomic Energy Commission guide provide guidance on preparing a measurement control procedure. 

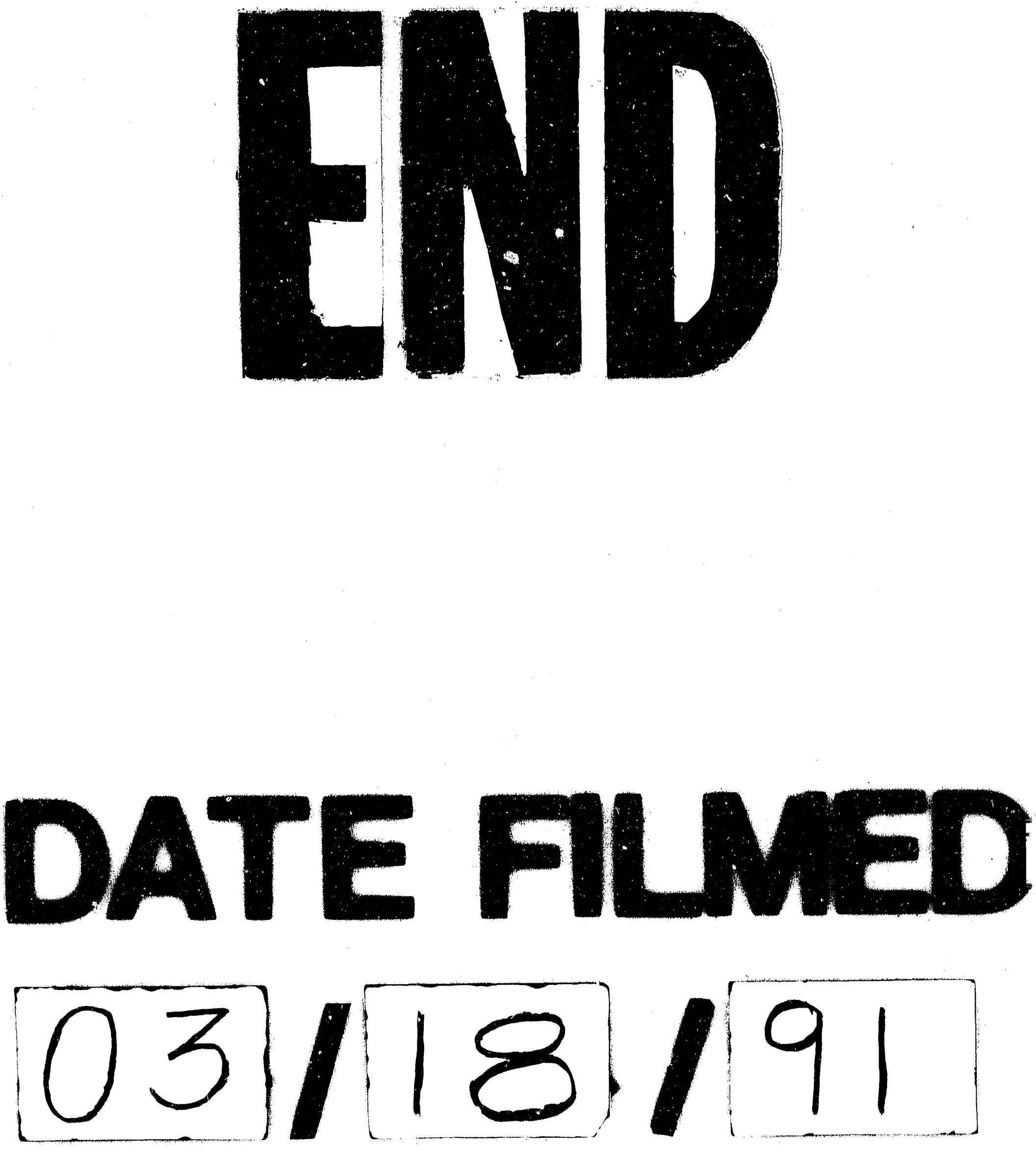
